\title{
德意志民主共和國農業 五年計劃㯙况
}

沈 其 益

1952 年 11 月, 我因篇出席了在柏林舉行的 國際植物保護會議, 會後得到德意志民主共和國 费業部部長斯學滋博士和農業科學院院長斯眖培 数授的聲助, 寥觀了農業科學院的研究所、柏林 大學農學院和拖拉機站等機構, 蓝且得有機會和 民主德國傑出的農業科學家（如農業利學院副院 長貝克敉授、院士貝拉赫敉授、院士阿伯多夫 数授、研究所所長玉柏森博士、柏林大學包門呚 授、農業部的何夫門博士和摩偕科博士等)會談,

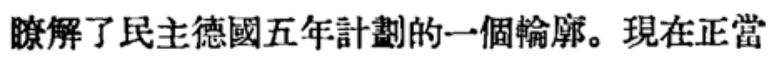
我們祖國進行第一個五年計劃建設的時候, 特地 把這些梠料整理出柬，作一個概括的介紹。

\section{戦後民主德國農業的改造和弡展}

第二次世界大戰結束後, 尼主德國在蘇聯紅

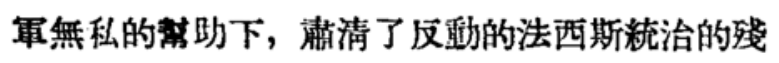
餘; 展開了大規模的印主改革運動。工業方面把 大小工僘、公用事業收路國有。銀行和大商店也 收賋國有。在廣大的農村中自 1945 年到 1947 年 撒起了偉大的土地改革運動。這個土地改革運 動, 就堡定了尼主德國農業改革和進一步發展的 基礎。

土地改革以前, 由於“容克”地主階釉的殘酷 掠煲, 土地和其他農業生產资料的分配是極不平 衡的。佔人口 $1.1 \%$ 的地主（佔有土地 100 公頃 以上）掠蔀了整個耕地面稳 $29.6 \%$ 。而佔 農 業 人口 $89 \%$ 的中小辳（他們的土地最多不超過 20 公頃) 只有全部土地的 $40.3 \%$ 。通過偉大的土地改 革運動, 把超過 100 公頃以上地主的土地加以沒 收, 分配給贫维農、特别缺地的小農和新要户。
這榡就使 200 萬公顷的土地分配給了 50 瓷的勞 䂛人民。在土地的分祀上起了質的變化, 那就是 說, 全部土地的 $75 \%$ 篇中小農所有。在土地改 革的運動中勞動農比還分得11沼所住宅和農場建 築物, 44 萬頭牲畜, 6,000 部拖拉機和 27 常具各 種農具。

由於土地改革的結果, 蕀固了工人階級和農 民的聯盟。農村中出現了一片新氮象。農上除獲 得了土地外還從政府方面得到了很多勘。首先 是得到了 3 檍以上的長期貸款, 以便佈㯰他們的 農場建策物。並且他們從國營脤場得到了俊良種 子和良種牲者; 從抬拉機站得到株作收獲等田間

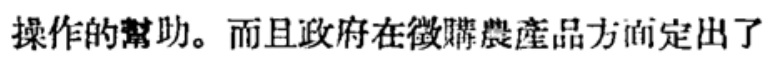

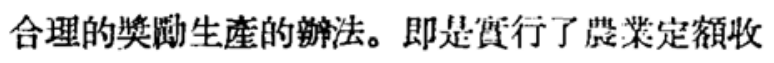

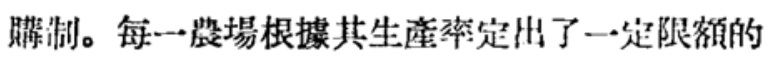
收期。農尼於繳付政府一定数额外, 其因提高生

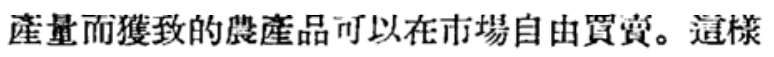
可以得到较高的代僄，以交換其所需的工業用品。

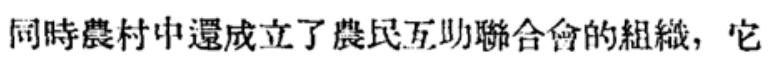
的主要任㹣是通過租借農具, 組織生產无此, 促 進農村中進步民主的發展。這一系列的楛放, 稳

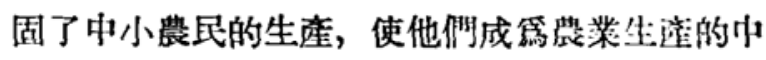
堅。由於他們的勞動，現在已供㮣着國家 $70 \%$ 的敨物和 $75 \%$ 的肉類。中小農包就成了宸村中的 主要成份, 他們在工人階級領導下, 完成了脤村 中的昆主改革運動, 現在正在努力發展生隌。

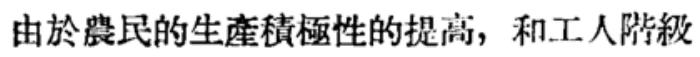
的堼助, 月前農業生産量就已絕大大的超遥戰前 的水平。我們可以舉出幾種作物和牲畜的産量來 加以說明。 


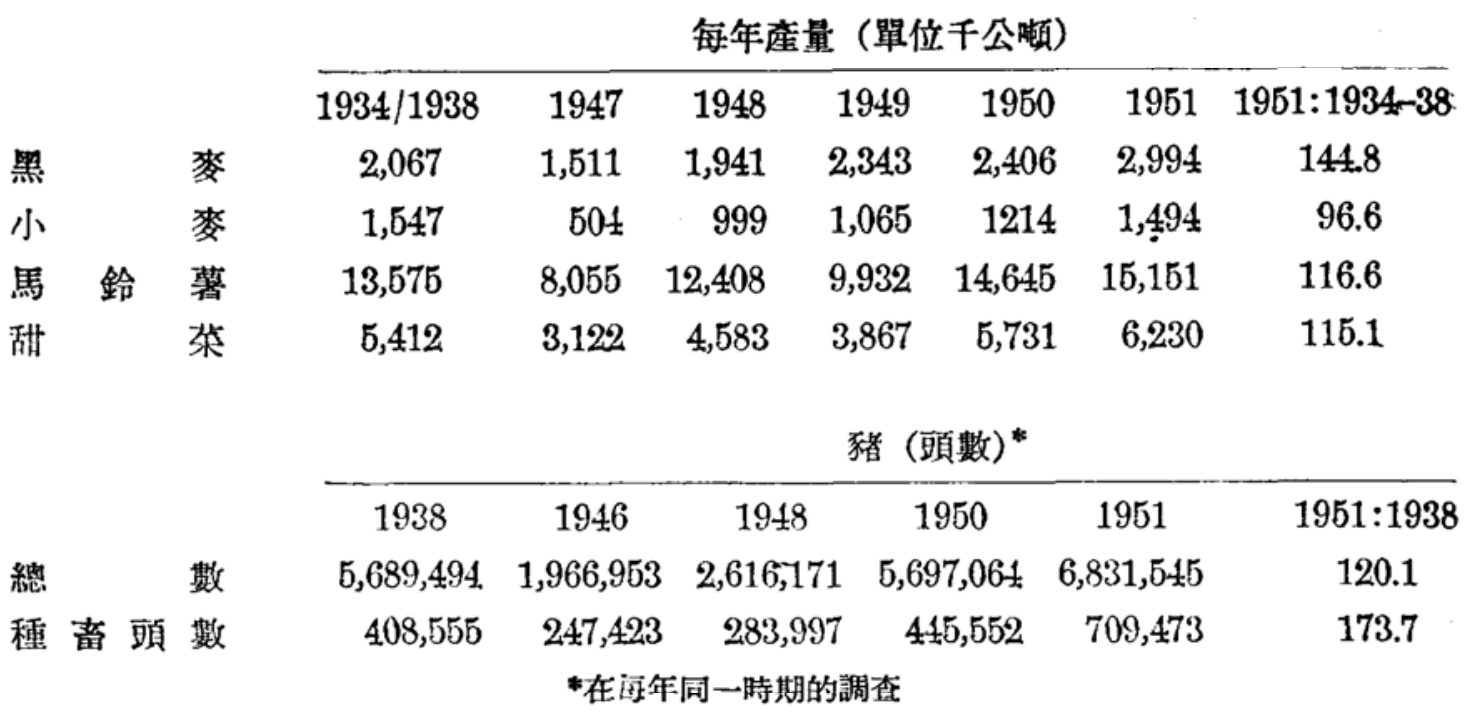

以上的數字表明在土改後農業生產的急劇上 昇的情况。我們隹融指出, 這種偉大的成就只有 在土地改革以後, 制别階狳已經從根本上被㔊除 和消诚，在進一步乵固了的工農聯盟的基礎上才 能獲得的。這核也就以事賽駁哌了帝國主義的造 兓, 說什窊因篇土地改革, 土地分散將使農業生 產下降的荒琴的惡意中傷的欺騙言論。

\section{民主德國五年計劃的總任務}

民主德國的農業建設五年計劃是在農村中已 經赛行了土地改革，㖘業生產已經飛躍地向前發 展着, 工農聯盟的基礎已經翠固了的基礎上進行 的。

民主德國農業建設的五尔計劃，也是整個國 家建設五年計㓶的一部份，因此要了解農業五年 計劃, 首先得把五年計劃的主要內容加以概括的 說明。

民主德國的五年計割是一個和平建設 的計 割, 也是一個戰的的任務, 它的主要目的就是要 通過計劃生產提高人民生活水平, 爭取和平和德 國統一的宾現。在五年計劃中規定和平工業產品 要達到 1950 年的 $192.3 \%$, 那就是說要超過戰前 生產水平的二倍。(1936 年工業生產總隹是 212 億馬克, 到 1955 年要上最到 450 億馬克)。五年 計劃規定農業生產總值要增加 $57 \%$ 以上。此外五 年計劃規定工人工資要增加 $31 \%$; 食物價格減低 $28 \%$ 。同時要撥除配給俳，減低勞動人比賦梲的 負担。

五年計劃中規定要減低生產成本，反對浪費。
䉆着達到這個目的就要使各項生產品標準化, 增 加工作㸮力, 加强機械生産的現代化, 節約材料, 減少麿品, 使生產成本降低 $26.8 \%$ 。

五年計劃規定 1955 年國家收入總值第 1950 年的 $160 \%$ 。由於國家收入的坦加, 國家才有能 才提高人民的物質和文化生活的水华。在提高人 民的文化生活方河, 五年計割中, 要大力墢展科 學、文化和藝術; 要發展各級學校, 大力培㖉青 年的一代。

在五年計劃中規定要加强對國外留易, 首先 是和蘇聯、中國及其他人民武主國家的留易。要 加强人民民主陣焒的力量, 以爭取德國的梳一和 世界的持久和平。

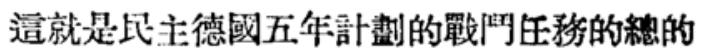
內容。

\section{五年計劃中農業生産的任務}

在䢅業生產方面，五年計劃的方針佂務就是

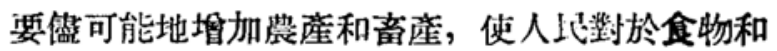
營笭品的偖長的要求, 得到大部份的自給, 對於 工業原料的要求, 僳可能予以供應; 即要使全國 人民可以得到较多的生活資料。農包得到较多的. 工業製品, 使農村的文化水平逐步提高。

在五年計稩中規定 1955 年的播種面皘是 $5,126,000$ 公頃。较 1950 年坦加 $2.3 \%$ 。德國耕 地䤄積的坦加有很大的限泚, 因此在五年計劃中 要集中力量增加單位面啨的產量。在五年計劃中 規定 1955 年各種作物的來均应量, 總產量 和興 1950 比較提高的百分比如下: 


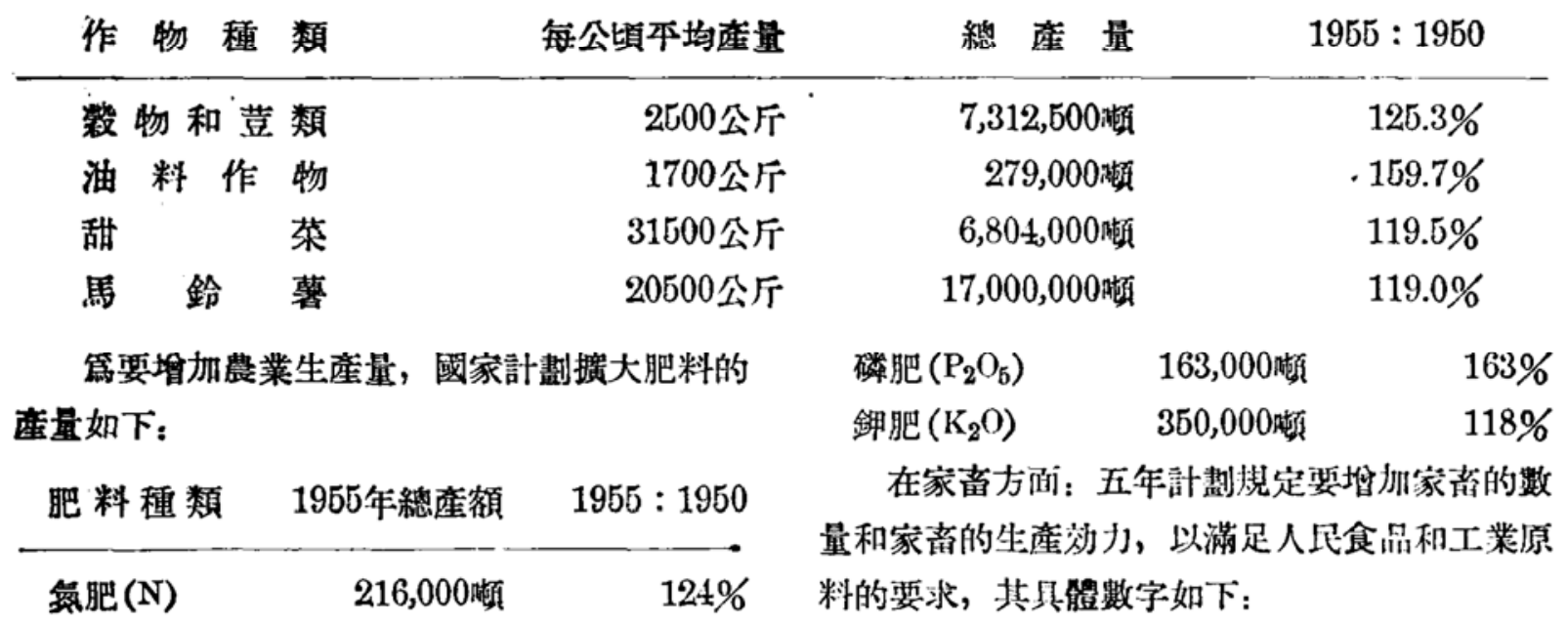

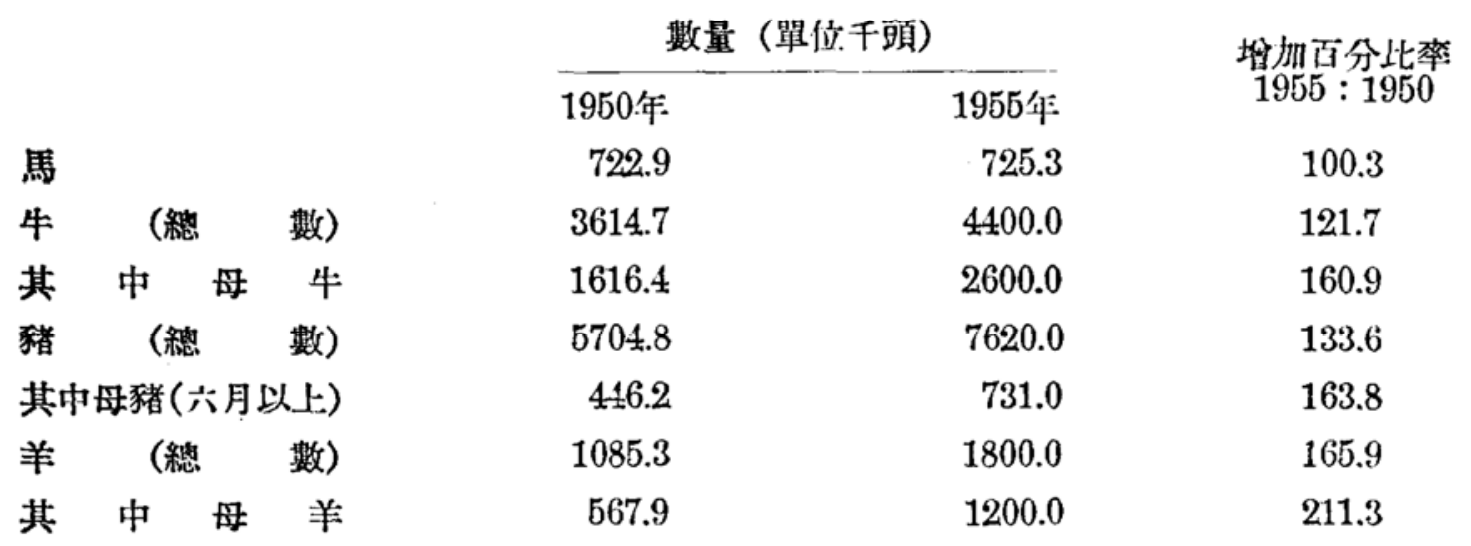

在生效効力上, 每一牲音的平均座量也要求提高如下:

1950

牛的產奶量 (每部会年量是 $3.2 \%$ 基脂 $)$

猪的産肉量(殺後浮重)

牛的磪肉量(殺後浮重)

$$
\begin{aligned}
& 2130.5 \text { 公厅 } \\
& 100.0 \text { 公厅 } \\
& 181.0 \text { 公厅 }
\end{aligned}
$$

1955

$$
\begin{aligned}
& 2650 \text { 公厅 } \\
& 115 \text { 公厅 } \\
& 250 \text { 公厅 }
\end{aligned}
$$

1955:1950

$124.4 \%$

$115.0 \%$

$138.1 \%$

1955年㹣類、奶品、鴙蛋達到的總要求如下:

$$
19551955: 1938
$$

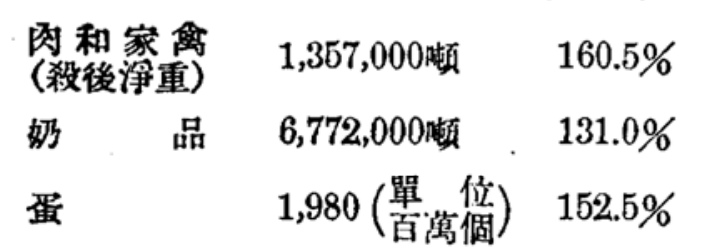

以上列舉的數字就是五年計劃在農業生產上。 所規定的總的任務。篬要達到道樣高額生產的總 任務。民主德國正在加强拖拉機站、國營㖘場、 發展灌業科學研究, 學習和推廣蘇聯農業科學先

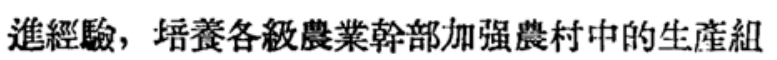
織, 墢展經濟和提高政治和文化生活的工作, 現 在再把邆些工作加以概括的叙述。
拖拉機站的任務

尼主德國是工業發達的國家, 虹業人口不到 總人口 $30 \%$, 因此勞動力罣常缺乏, 耐且在五年 計劃中, 工業生產上還不斷要從譨村小吸取勞㔚 力, 因此㖘業生産的全盤機㳦化是十分重要的。 在戰後鲎啨業生產勞哺力極端缺乏的時候, 蘇聯紅軍筸在 1949 年: 給予了域主德國無私的幫

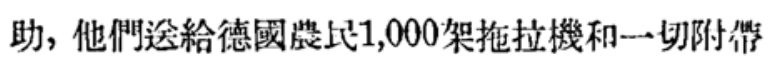

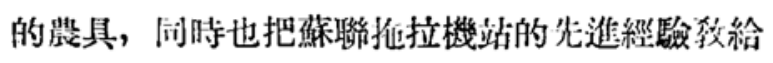
了他們。因此在 1949 年德國就開始設立了拒拉機 站, 從此以後, 拖拉機站的工作浴力一直不断地 在提高着。

五年計劃中規定拖拉機站的数目將要從 1951 年的 524 站增加到 1955 年的750 站, 共增226站。 
其中拖拉機站的各種農具增加的数量如下:

1951

拖 拉 機

10,834

37,500

拖 拉 機犁

10,654

38,500

拖拉機耕耘機

2,323

12,100

拖拉機播種機

820

6,600

拖拉機割麥機

4,383

10,500

打 款 機

7,072

8,350

在增加了這些機器農具以後, 在 1955 年預計 用拖拉機耕種的土地要達到 $6,900,000$ 公頃。其 工作效力要比 1950 年增加 $42 \%$ 。

國家設置拖拉機站的主要任務就是要用新式 的農業機器幫助勞動人民, 首先是中小農户的耕 作。此外拖拉機站還要給予農民科學技術的指導, 提高農產和音產。弡展農村中的互助合作縕織， 提高農村文化生活和加强工農聯盟。

在拖拉機站初成立的時候, 因篇限於機械的 種類, 當時只限於耕地、收磪和脫䊀。現在逐船 增加了以下的項目：如播種峘物、甜荣和馬鈴薯 中耕作物的中耕操作以及馬鈴著和甜获的收穕。 這樣適罍地減輕了農忙時的工作。

篇提高工作効力，拖拉機站都實行了輸班制 度, 即每日24小時分篇二班到三班, 日夜輪流工 作, 每班工作 8 小時, 充分發掉了機器的效能, 同時解决了季簛性農忙的工作的困難。

拖拉機站首先是繁助互助組合作和和中小農 的耕作。一般是用訂合同的制度隶規定工作的計 劃性，按着工作的性啠收費。但是，對一般只有 十公頃地的小農, 收費也較少。

拖拉機沙除了本身要提高工作劫力減低成本 加强對機器的保養, 䨢行輸班制, 及時耕作保證 質量之外，它還負有指導農鸟生產的任汾。在一 般情形下可在農閑的時候開設訓練旺，敎授浘上民 及其子女以新的科學技術。拖拉機站的文化宫要 使之成第㖘民中民主和交化活酯的中心。

在五年計鄙完成的時候要達到所有由問洨重 的耕作和一部份的音産工作都要能用機器操作代 替人力。

\section{國營農場的任務}

比主德國在惯行土改中，汥收了地主階級的 土地, 將其中的一部份設立了五百個國營農場。
這些國營農場的主要任预: 就是應用先進的生產 技術, 特別是蘇聯先進的生產技術, 在它所在的 地區, 研究一夽適用於賞地的生產技術, 提高生

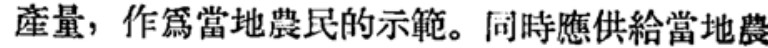
民以作良種子和牲畜。在五年計敖中國營農場要 發展成篇示範的機㑘化的高額生產的農場。五年. 計劃中對國營農埸提出了幾種主要作物單位面皘 的平均産量如下:

\begin{tabular}{|c|c|c|}
\hline 没類及壹類 & 每公顷 & 3,100 公厅 \\
\hline 料作物 & 每公頃 & 20,00 公厅 \\
\hline 获 & 每公頃 & 34,500 公厅 \\
\hline 鈴 著 & 每公頃 & 22,000 \\
\hline
\end{tabular}

上主德國國營農場縕織的初期, 也會存在着 啒重的官僚主義, 遭受着資有階級思想與經營方 式的影響, 因此很少進步, 很多不能自給, 因而 也不可能起示範的作用。因此黨和政府就大力領 尊工作人員認旨學習蘇聯的先進生產技術, 實行 艮主改革和合理的管理制度。

第着提高國營農埸的工作㸮力, 首先要使場 員明膫農場工作的全盤計劃, 鼓舞全體工作人員。 例如拖拉機手生產榢長用競寒的方法和隨時提出 合理化建議以改進和推進工作。在工資上應執行 工作日的制度，按勞取酬，以提高場員的皘極 性。在科學技術上應加强學習蘇聯, 克服資産階 級陳鹤的保守觀等。

在生產侵良的作物和牲音品種方酌, 國營浱 埸的技術人員要和科學家們保持密切的合作，有 計劃地培育良種。京時各國營農場要根據自己的 條件在培育良種上要踶行一定程度的軎菜化, 這 柡才能集中力量推動工作。

國營農場必須加强農業生產的機械化，把提 高生產繁殖良種的方解加以凘徽。在1953年的計 劃中規定國營農埸要供給國家 100,000 噸的肉類, 這就是要在1953年較1952年增痤 4 倍。在二、三

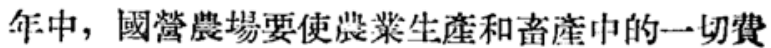
力的操作使用機械來替代。

\section{改進技術提高産量}

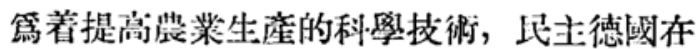

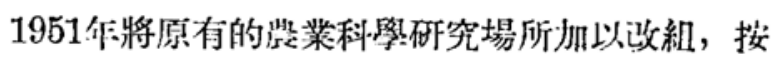
照蘇距農栄科學院的榜樣, 組成了圤主德成的農 業科學院, 農業科學院的主要任扮是諝求㖘業科 
舆的新婈展, 學習蘇聯的先進科學, 使科學知識 傮速地應用於農業生產, 完成或超額完成五年計 㔊所規的㖘業生產任肦。

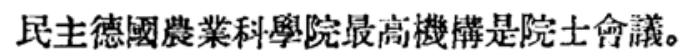
院士是由政府就農業科學的领域中挑選權威科學 家担任的。現有院士27人, 這些院士按其學科分 雼 9 組, 即 (1) 農業經流 (2) 土壤、植物營䖭及 耕作（3）作物戊埰、㕕種及洍物保護（4）園

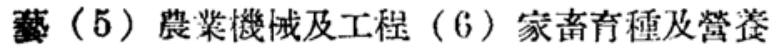
（7）獸䣽（8）森林（9）图林風景及自然保 櫵。每組除由院士參加外, 遙有從事斯際工作及

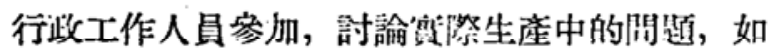

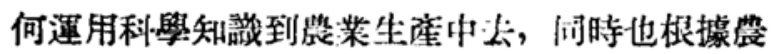
業生産的要求决定科學研究工作的方向和途徑。

䉆着其徽研究工作，臀業科學院领導了專業 研究所和分場共 37 單位, 同時她還和科學院及 大學取得泌切的聯祭, 她經常派遣軎家到農村、

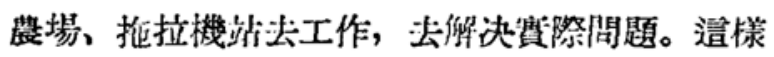
加强了理論與蟥践的統一, 也加强了整個研究工 作的計䁬性。

通過各小組討論和全院院上 會議, 就 可以

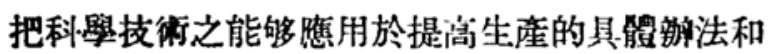
措施向辳林部建議, 造些建議即可由辳林部分别 傳達到拖拉機站、國營農場等機構來進行, 战者 是通過出版物和廣播加以介紹。

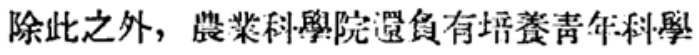
家的责任, 加强科學研究工作中新生的力量。

改進贯業生產技術的主要方面是學皙蘇聯, 把米压林、威庵士和李森科的學說, 和德國的生 虚呫際結合起夾。

首先是運用草田輸作制, 改善土埪的園粒結 構, 提高土壤的肥沃性。在粗放經營的地區可以 探用多年生牧草; 在集約經營地區, 他們正大量 推廣間作的方法, 一面提高土壤的肥沃性, 一方 面也佯决了坦加畜產而柃料缺之的間題。其方法 就是在秋季冬種作物播種以後, 在田地中加播豆 類和禾本科牧草的混合種子, 在冬季作物收獲後, 牧草還是繼緮生長在田地中, 到秋季, 牧草可割 刈一次, 明年春季還可收割一次, 以後就可以翻 耕。道樣可以增加土壤的肥沃性, 闹時也解决了 飼料問題, 對發展音牧業是十分有利的。

在䅛施肥料上, 德國政府正大量地生產氮肥
磷肥和鉀肥。而在磷肥的施用上, 德域正在利用! 顆粒磷肥, 因第這樈可以使磷肥的有㳔利用坦加; 3 一 5 倍。

民主德阀的音牧業佔整個宸業生產的比重的 60\%, 因此它佔着十分重要的地位。在學空蘇聯方

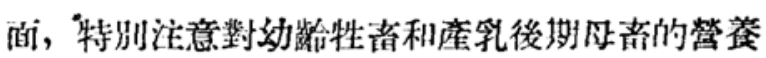

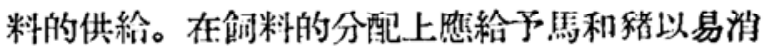
化的鸰料, 對反留動物则可以給予營荃料较少的

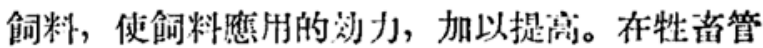

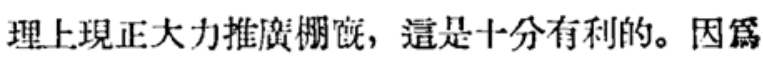
在五年訃敖中要大量繁殖牲音，不可能有這㥞多

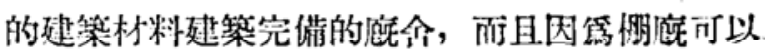

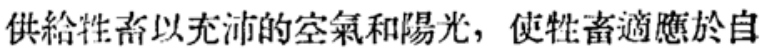
然氣候的變化，也增加了家部對於次病的 抵抗 力，特別是牛對明結核的抵抗能力。

痤家音育種方䤄正大量隹用人工授精的方法

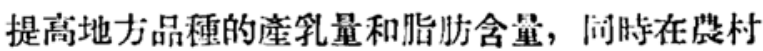

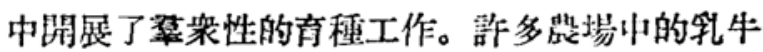
逹到 6,000 公厅芷至達到了 10,000 公厅的高額産 量, 只是在脂肪含量上還要败進。

在作物育種方泊，也有很多的成絖，例如，

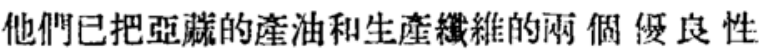

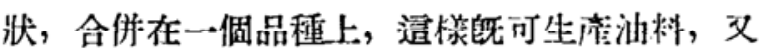

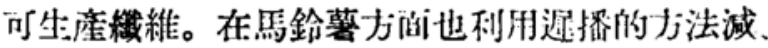

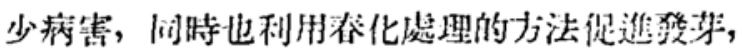

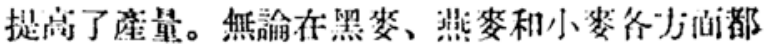

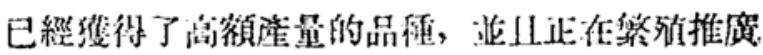
中。

此外在耕作中澴適賞地坦加耕地的深度, 除

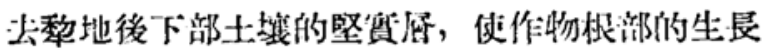
墢育和水份營食的吸收都能堆加。除此以外, 對 植物病品的防治和家音的保櫵工作也有很大的進

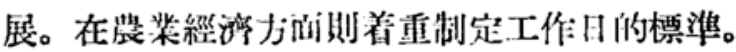

\section{弡展農村互助合作的生産組織， 提高㖓村的文化生活}

戰後的六倜年代裹由於湿村小熋行了上主改

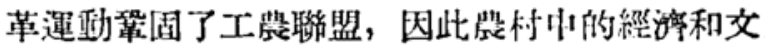
化生活已在鿊钦發展之中。

在經淙方面就組織了農民百助聯合留。它的 主要任務是通過拖拉機站, 組織㖘地互助, 断 農民獲得生活和生產必需的工業產品, 促進農村 
吓民主運動的發展。同時它還破動了農業生產的 一競賽, 推㲜生產, 增加了農胞的收益,

但是由於土地過於分散, 限制了新的農業生 產技術和大型農具的應用, 因此黨的第二次會議 上决定在互助的基礎上發展生產合作社的組織。 渟個决議得到農民的熱烈響應和支持。1952年在 7 月份組織了59 社， 8 月 160 社，9月387动，10月 855 社, 到11月就上杽到 1,335 䇆, 共有社員人數 22,174 人, 耕種面積達 113,750 公頃。組織生產

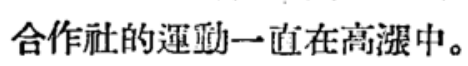

德國農業生產合作社分黨三種類型。第一種 只是土地入㼛, 園地、牧場、牲音、機械、農具 還是榈人私有的。第二類型除土地入社外, 農 具、機械和一部份役畜入社, 但是機械、農具、役畜 是由社筫買, 在十年以內由衤還清。第三類型是 把土地 (包括牧地和森林)、農具和牲畜（役畜以 及大部份的種音）速同房舍入社, 共同經營。機 械、農具、牲畜不是由施䑏買而是作價入股。在以 上三種類型中, 莵上都保持土地的所有權。目前 德國的生產合作社以第一、二種類型最多, 第三 種才開始。這三種類型的精神是一致的, 都是從 個體經營, 逐步走向社會主義的經濟形式。

民主德國的合作社運勘現在還在繼續舫固的 階段, 就目前來誶, 他們必須做好秋收、冬耕和春 季播種前的一切準備工作, 如種子、農具、牲畜 等, 使來年的生産獲得保證。在經營管理方面要 執行工作日的制度。在健全組織方面, 要把具有 農業生產知識、組織才能的人物選爫生產榢長來 “領導工作, 開展競寒運呩, 以獲致高額產量。

在1953年各生產合作社要定出全年的生產計

劃。提高生鏟效力。惯行完善的簿記制度。

民主德國的農業生產合作社運動還在不斷的 發展中, 它的帜固和發展, 對於提高生產、提高 農村中的政治和文化生活、保登五年計劃的算行, 將起决定性的作用。

提高農村中的文化生活是以拖拉機站國營農 場第中心, 通過組織各種講演、電影、檴狚班、
圖書舘和國營濃場來進行的。首先拖拉機站的费 學家、畜牧學家要向宸把推廣新的科學技術, 敎 育他們及其子女以先進生產技術, 在農䦥的時候 第他們開課, 同時脤上自己也組織了米丘林小組 來進行學晳和賽驗研究工作, 以提高産量。

在五年計劃中還規定要培食各級專門人才, 使不斷有新生的力量參加到農業生虐的戰綫中 去, 长主德國除開在大學和高等學校培食高級科 學技術人員以外, 還着重在國營農場、拖拉機站 用訓練學徒的方法, 在盤践中培食大量的中級技 沺幹部。這些人才經過触際工作一個階段後, 選 可以什入大學, 提高理諭水平。

且主德國五年計劃執行以隶, 由於政府的正 確領導和廣大人圮的支持, 已經戰勝了一切困 難, 向着勝利的迄路上前進。他們還在篇完成下

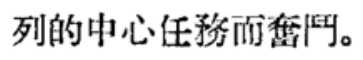

1.學晳和應用先進農業科學的成果。

2. 加强在高等學校和中等職業學校中培䓹各 級農業專家的工作, 大量地培養拖拉機手和農業 經營管理的各方面的人才。

3. 應用先進的工作方法從技術的基礎上確定 工作日的標準, 有計劃地有步驟地減低機械耕作 的成本。

4. 在國營農場触行經濟核算制, 使國營農場 經管上能够獲得利谷。使國營農場起着示範的作 用。

5. 把農業勞動者組織在民主組織 的工作中 來。研究減低農鸟所負担的農業稅, 和保障農民 權谷的法律。

6. 加强農民的互趿協會, 加强農業生產合作 㼛的組織和生產工作。

7 . 通過農均的互助協會、生產合作旅, 加强 對於宸民工業品的供應, 提高農切的生產和生活 水平。

8. 提高莀村中的民主生活, 普及知識, 提高 交化水平。 